\title{
Incision and snaring: a simple trick to grasp flat colonic lesions
}

Endoscopic mucosal resection (EMR) is, nowadays, a well-standardized therapeutic technique for the treatment of gastrointestinal (GI) neoplasm limited to the mucosal layer. EMR is indicated for the removal of sessile or flat polyps smaller than $2 \mathrm{~cm}$ or for piecemeal removal of larger lesions [1]. Compared with EMR, endoscopic submucosal dissection (ESD) results in a higher en bloc resection rate and lower local recurrence rate, yet ESD has high procedure-related complication rates and is more time-consuming [2]. Especially in presence of flat lesions, grasping the lesions can be challenging. A hybrid technique solved this problem, although it is also a time-consuming procedure [3]. When sessile or flat lesions can be removed by EMR, one simple trick for grasping the lesion is, after submucosal injection, to create an incision in the normal mucosa in the fold beyond the proximal edge of the lesion where the tip of the snare will be inserted. Afterwards the scope is withdrawn slowly until the snare is completely open. Then the lesion can be grasped, deflating the bowel, and cut ( $\vee$ Video 1 ).

Endoscopy_UCTN_Code_TTT_1AO_2AG

\section{Competing interests}

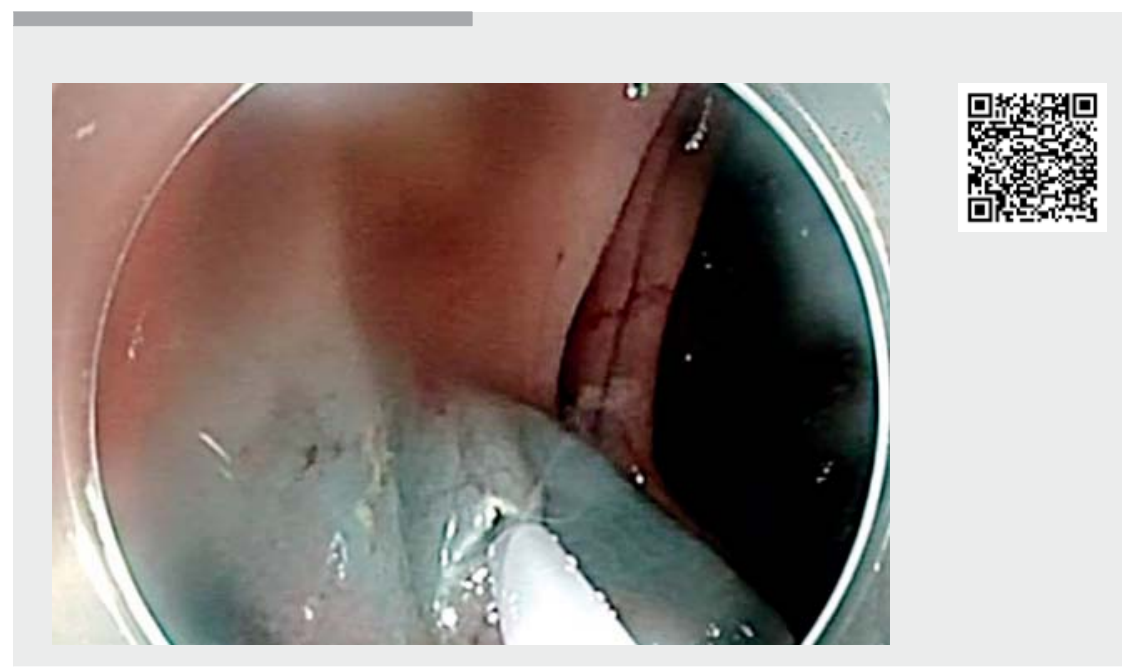

Video 1 Incision and snaring technique for grasping and removing a colonic flat polyp.

The authors

Benedetto Mangiavillano ${ }^{1,3}$, Francesco Auriemma ${ }^{1}$, Mario Bianchetti ${ }^{1}$, Roberta Maselli ${ }^{2,3}$, Alessia Galtieri ${ }^{2}$, Alessandro Repici ${ }^{2,3}$

1 Gastrointestinal Endoscopy Unit Humanitas Mater Domini - Castellanza, Italy

2 Digestive Endoscopy Unit, Istituto Clinico Humanitas Research Hospital, Milan, Italy

3 Humanitas University, Milan, Italy

\section{Corresponding author}

Benedetto Mangiavillano, MD

Gastrointestinal Endoscopy Unit, Humanitas

- Mater Domini, Via Gerenzano n.2,

21053 - Castellanza (VA), Italy

Fax: +39-0331-476210

bennymangiavillano@gmail.com

None 


\section{References}

[1] Masci E, Viale E, Notaristefano $C$ et al. Endoscopic mucosal resection in high- and lowvolume centers: a prospective multicentric study. Surg Endosc 2013; 27: 3799-3805

[2] De Ceglie A, Hassan C, Mangiavillano B et al. Endoscopic mucosal resection and endoscopic submucosal dissection for colorectal lesions: A systematic review. Crit Rev Oncol Hematol 2016; 104: 138-155

[3] Okamoto K, Muguruma N, Kagemoto K et al. Efficacy of hybrid endoscopic submucosal dissection (ESD) as a rescue treatment in difficult colorectal ESD cases. Dig Endosc 2017; 29 (Suppl. 02): 45-52

\section{Bibliography}

DOI https://doi.org/10.1055/a-1047-4316

Published online: 2.12.2019

Endoscopy 2020; 52: 413

(c) Georg Thieme Verlag KC

Stuttgart · New York

ISSN 0013-726X

\section{ENDOSCOPY E-VIDEOS}

https://eref.thieme.de/e-videos

回局 Endoscopy E-Videos is a free access online section, reporting 靣: on interesting cases and new techniques in gastroenterological endoscopy. All papers include a high quality video and all contributions are freely accessible online.

This section has its own submission website at

https://mc.manuscriptcentral.com/e-videos 